\title{
POBREZA E DESIGUALDADE SOCIAL NAS ESCOLAS DO NÚCLEO RURAL DO MUNICÍPIO DE PARAÚ-RN
}

\section{ARTIGO ORIGINAL}

ROCHA, Magna Maria da Conceição ${ }^{1}$

ROCHA, Magna Maria da Conceição. Pobreza e desigualdade social nas escolas do núcleo rural do município de Paraú-RN. Revista Científica Multidisciplinar Núcleo do Conhecimento. Ano 06, Ed. 12, Vol. 08, pp. 89-101. Dezembro de 2021. ISSN: 2448-0959, Link de acesso: https://www.nucleodoconhecimento.com.br/educacao/desigualdade-social, DOI: 10.32749/nucleodoconhecimento.com.br/educacao/desigualdade-social

\section{RESUMO}

Falar sobre a pobreza e desigualdade social é um desafio que nos remete a vários aspectos da existência humana e do ser social. Entendemos que a superação da pobreza é ou está condicionada a evolução do ser humano quanto à aquisição e evolução como ser social. Diante do exposto, o presente artigo, tem como questão norteadora: Qual o nível de pobreza e desigualdade social nas escolas da zona rural do município Paraú? Tem como objetivo analisar o nível de pobreza e desigualdade social nas escolas do núcleo rural do município de Paraú - RN e apresentar suas causas e consequências. Para isto, foi realizada uma análise quantitativa de levantamento de dados, utilizando um questionário misto (questões abertas e fechadas) composto de 7 (sete) questionamentos para os segmentos: escola e comunidade escolar. Com base nos dados colhidos identifica-se que a maior parte dos entrevistados se declara pobre e não conhece o conceito de desigualdade social. Chega-se à conclusão de que a pobreza e a desigualdade social nas escolas

\footnotetext{
${ }^{1}$ Especialista em Mídias na Educação (UERN), Especialista em Educação Especial e Inclusiva (FAVENI), Especialista em Educação, Pobreza e Desigualdade Social (UFRN), Especialista em Coordenação Pedagógica (UFRN). Graduada em História (UERN). ORCID: 0000-0002-1911-6666.
}

RC: 103668

Disponível em: https://www.nucleodoconhecimento.com.br/educacao/desigualdadesocial 
in loco, são fatores de exclusão política e social, demonstrando a necessidade de políticas públicas que atendam a população presente nestas escolas.

Palavras-chave: Educação, Pobreza, Escola, Sociedade.

\section{INTRODUÇÃO}

A pobreza é uma problemática que incide sobre diversos aspectos da vida de uma população. No Brasil, apesar dos avanços tecnológicos, cultural e econômico, o nível de pobreza não tem sido minimizado efetivamente em grande parcela das famílias brasileiras. O que pode ser observado, ainda, é que no dia a dia as desigualdades sociais se acirram de forma preocupante, pois não há nenhuma atitude por parte da sociedade, bem como do poder público sobre essa questão. $O$ que existe são projetos, programas e ações que minimizam o sofrimento de algumas pessoas, porém não as imunizam de certas questões, como é o caso da pobreza. É importante percebermos que esta é a expressão direta das relações vigentes na sociedade, às quais são extremamente desiguais, em que convivem em uma mesma conjuntura, acumulação e miséria, mecanismos que atribui aos pobres um lugar à margem da sociedade. Falar sobre pobreza aos pobres é, pois, adentrar em um território onde existe um sentimento de revolta, gerado por inúmeros fatores que persistem em aflorar dimensões aliadas a insistência de sobreviver, como relata Yazbek (2010).

A renda é um elemento importante para a definição de pobreza, mas não determinante para configurar o sujeito como tal, pois há pobres que têm acesso a recursos e serviços materiais e são carentes em aspectos, como informações, anseios etc. O que devemos levar como algo realmente importante é que a pobreza não é somente não ter bens materiais, mas também não ter direito, oportunidades, acesso às informações, possibilidades e esperanças, como preconizado por Martins (1991), em seu livro "O massacre dos inocentes". 
A educação é uma peça fundamental para que a realidade possa ser mudada de forma evolutiva. Neste contexto, discutiremos sobre a "Pobreza e Desigualdade Social nas escolas do núcleo rural do município de Paraú/RN", localizado na microrregião do Médio Oeste. Portanto, levantou-se a seguinte questão norteadora: Qual o nível de pobreza e desigualdade social nas escolas da zona rural do município Paraú? De modo mais específico, o objetivo é analisar o nível de pobreza e desigualdade social bem como suas causas e consequências no referido lócus.

Para isso, foram aplicados questionários mistos (compostos por questões objetivas e subjetivas) com funcionários das escolas[2] - professores - e com representantes das famílias das comunidades rurais - pai e mãe -, abordando os eixos: Pobreza; Desigualdade Social; Educação. A escolha metodológica da aplicação do questionário foi firmada em Severino (2007) e Demo (1982). Os dados coletados estão apresentados através de tabelas com comentários interpretativos fundamentados nos autores Souza (2009) e Arroyo (2013).

Assim sendo, este artigo se organiza da seguinte forma: primeiro, há uma discussão acerca da "Pobreza e Desigualdade Social" em linha geral, em seguida, apresentamos informações históricas e específicas sobre o município de Paraú/RN e suas escolas do núcleo rural - lócus da pesquisa -, posteriormente, há uma mostra dos dados coletados bem como sua análise a fim de identificar o nível, causas e consequências da pobreza e da desigualdade social no contexto explorado.

\section{POBREZA E DESIGUALDADE SOCIAL}

Vivemos em um mundo de pessoas diferentes. Essas diferenças se baseiam em raça, gênero, cultura, condições materiais, entre outras coisas. É fácil identificarmos uma pessoa de um determinado grupo social diferente, com base em valores adotados pela sociedade. Souza (2009) afirma que, "em sociedades com alto nível de desigualdade, o processo de transmissão de saber e de conhecimento superiores permanece restrito às elites". Acontece, então, a desigualdade social e junto a esta, 
a dificuldade de enxergar o mundo com sua multiplicidade e o resultado disso é discriminar os que não atendem aos padrões.

A educação é o aspecto mais afetado pela desigualdade social, e que também contribui para acentuar a pobreza. O processo educativo torna-se excludente quando seleciona o aluno que vai evoluir e o que não vai esquecendo sua principal função, que é trabalhar cada indivíduo de forma a contribuir com sua ascensão educacional e profissional. Hoje, ainda existe o ensino padronizado, aulas obrigatórias, divisão de séries, currículos desvinculados da realidade, pressões por parte dos professores, que por sua vez são pressionados por coordenadores e diretores, desmotivação, horários rígidos e uma estrutura vertical. Enfim, neste quadro, quem vai para a escola com a perspectiva de mudança, e, sobretudo, de ascensão profissional, se depara com essa realidade, que contribui com os interesses da classe dominadora.

Consideramos, pois, a pobreza como consequência (da junção) de diversos fatores, como: a geração de empregos que não acompanha o crescimento populacional, de modo que o mercado de trabalho não consegue inserir todos os trabalhadores; a falta de escolarização, pois os currículos não estão envolvendo as pessoas que procuram a escola em busca de um nível educacional que os preparem para o mercado de trabalho, além disso, mesmo quando existe, algum órgão de formação inviabiliza a participação das mesmas, uma vez que não dispõe de recursos para arcar com as despesas e, quando são públicos, se deparam com a burocracia de documentação. Somado a estes fatores, a má distribuição da renda, também, caracteriza a pobreza e extrema pobreza. Assim, não existe um conceito científico do que é a pobreza ou extrema pobreza, o que há, é uma caracterização política e social.

Em consonância, Destermeau e Salama, (2002) afirmam que: "O fato 'pobreza', qualquer que seja seu grau de definição, é sempre assimilado ao 'problema' da pobreza, seja no plano ideológico e moral, seja no plano político e econômico". Isto 
quer dizer que a significação de "pobreza" perpassa pelos mais diversos aspectos da vivência em sociedade.

Arroyo (2013), afirma em sua obra que "os coletivos empobrecidos politizam os currículos", ou seja, que temos uma visão ampla e moralizante da pobreza. A realidade da pobreza, atravessada pela desigualdade social, recebem mensagens traumáticas: as crianças, mulheres e idosos pobres, frequentemente, se chocam com frases depreciativas; os pobres, sofrem comumente o impacto dos maus tratos, a humilhação, o sentimento de não possuírem direitos, de parecerem desprezíveis e repugnantes.

\section{O MUNICÍPIO DE PARAÚ - RN E SUAS ESCOLAS DA ZONA RURAL}

No intuito de conhecer melhor o município de Paraú/RN e as escolas da zona rural será apresentado, inicialmente, um breve estudo histórico para, em seguida, adentrarmos quanto à sua configuração recente. Nesse sentido, destacamos que não há registros dos primeiros desbravadores desta terra, mas Cascudo (1968) em sua obra, "Nomes da Terra" descreve as limitações territoriais com seus respectivos proprietários:

...em 1734 era proprietário o Coronel Carlos de Azevedo do Vale, na Ribeira Açu. No Riacho Paraú, três léguas de comprido por uma de largo para o Rio PARAU DE BAIXO, pegando das testadas de Bento Teixeira chamado AS BELDROEGAS até as Várzeas das Caraúbas do RIACHO DO PARAU Chamado CURRALINHO, que deságua no RIO PARAU. Em 1777 a região estava povoada... (CASCUDO, 1968)

Para entender com mais clareza essas divisões, se faz necessário conhecer o Sistema Sesmarial que foi utilizado por Portugal, no Século XVIII, sistema esse que deu origem aos grandes latifúndios brasileiros. A Lei Sesmarial tinha como meta obrigar os proprietários a cultivarem as terras e, se assim não o fizessem, teriam que ceder parte delas para um agricultor realizar a tarefa. $O$ interessante sobre esse sistema, é que essas terras não eram tributadas (BIBLIOTECA NACIONAL, 1929)

RC: 103668

Disponível em: https://www.nucleodoconhecimento.com.br/educacao/desigualdadesocial 
Item o dito Capitão, e Governador, nem os que após elle vierem não poderão tomar terra alguma de Sesmaria na dita Capitania para si, nem para sua mulher, nem para o filho herdeiro della, antes darão e poderão dar, e repartir todas as ditas terras de Sesmaria a quaesquer pessoas de qualquer qualidade, e condição, que sejam, e Ihes bem parecer livremente sem foro, nem direito algum sómente o Dízimo de Deus que serão obrigados de pagar a Ordem de tudo o que nas ditas terras houverem segundo é declarado no foral, e pela mesma maneira as poderão dar, e repartir por seus filhos fóra do Morgado, e assim por seus parentes; e porém aos ditos seus filhos, e parentes não poderão dar mais terra do que derem, ou tiverem dada a qualquer outra pessoa estranha; e todas as ditas terras, que assim der de Anais do XXVI Simpósio Nacional de História - ANPUH - São Paulo, julho 20119 Sesmarias a uns, e a outros será conforme á Ordenação das Sesmarias, e com a obrigação dellas: as quaes terras o dito Capitão, e Governador, nem seus Sucessores não poderão em tempo algum tomar para si, nem para sua mulher, nem filho herdeiro como dito é, nem pol-as em outrem para depois virem a elles por modo algum que seja sómente as poderem haver por titulo de compra passados oito annos depois das taes terras serem aproveitadas, sem outra maneira, não. (BIBLIOTECA NACIONAL, 1929, p. 77).

A colonização destas terras se deu, como em todo território brasileiro, através de conflitos, nos quais os grandes proprietários, senhores de engenho e fazendas, manipulavam como desejavam os pequenos e raros proprietários que cultivavam suas terras; ao lado deles encontravam-se os agregados que geralmente eram escravos libertos, os quais prestavam todo tipo de serviços aos senhores das grandes fazendas. Essas desapropriações indevidas fizeram com que boa parte da população rural procurasse, nas cidades, meios de sobrevivências, gerando um índice alto de desempregados, uma vez que sem qualificação profissional não havia como encontrar meios de sustentabilidade, já que sua força de trabalho consistia em sua própria mão de obra.

O filosofo escocês Adam Smith (1983) apud Himmelfarb (1988, p. 55 - 79) em suas obras "Teoria dos Sentimentos Morais" e "Riqueza das nações", dizia que o patrimônio de todo o homem é o seu trabalho. Assim, o homem do campo é a confirmação do pensamento de Smith, de modo que suas habilidades estavam relacionadas a força do seu trabalho braçal e, suas esperanças, depositadas na pequena produção de suas lavouras, de onde era retirado seu sustento e de seus

Disponível em: https://www.nucleodoconhecimento.com.br/educacao/desigualdadesocial 
familiares. Com essas castrações, o homem do campo foi para a cidade - e a zona rural foi sendo abandonada e desprezada pelo sistema, o que acarretou o abandonado de casas e terras.

Num campo mais restrito, Paraú - que tinha em sua totalidade 39 Comunidades sofreu, nos últimos anos, com o êxodo rural, onde quase metade da população rural mudou de suas terras a procura de uma sobrevivência digna, com mais conforto. As políticas públicas (programas sociais, energia elétrica, adutoras, entre outros) chegaram tarde a estas comunidades rurais. A seca castigou o nordestino, obrigando-o a deixar suas terras em busca de melhorias, como retrata Luiz Gonzaga sua canção "A triste partida" (1964): "Sem chuva na terra. Descamba Janeiro. Depois fevereiro. E o mesmo verão. Meu Deus, meu Deus. Entonce o nortista. Pensandoconsigo. Diz: "isso é castigo. não chove mais não". (A Triste Partida GONZAGA, 1964).

Considerando esse contexto, a população rural de Paraú/RN caiu consideravelmente nas duas últimas décadas. Onde existiam aproximadamente 15 (quinze) escolas na zona rural do município, hoje, de acordo com o IBGE (2015), há somente 5 (cinco) escolas municipais, com o Ensino Fundamental e Educação de Jovens e Adultos. No ano de 2016 apenas 4 (quatro) funcionavam, com uma quantidade baixa de alunos. Tais escolas estão situadas nas comunidades de: Alagamar; Graça; Estrela do Oeste e Curralinho, no município de Paraú/RN, sendo geridas por um Diretor e duas Coordenadoras Pedagógicas, que atuam diariamente na Secretaria Municipal de Educação deste município.

Conforme dados do IBGE (2010), a população total do município era de 3.859[3] residentes, dos quais 563 se encontravam em situação de extrema pobreza, ou seja, com renda domiciliar per capita abaixo de $R \$ 70,00$. Isto significa que $14,6 \%$ da população municipal viviam nesta situação. Do total de extremamente pobres, $123(21,9 \%)$ viviam no meio rural e $440(78,1 \%)$ no meio urbano. 
Os dados demonstram, também, que no município havia 58 crianças na situação de extrema pobreza, com na faixa etária de 0 a 3 anos, e 37 na faixa entre 4 e 5 anos. O grupo de 6 a 14 anos, por sua vez, totalizou 128 indivíduos na extrema pobreza, enquanto no grupo de 15 a 17 anos, 30 jovens nesta situação. Foram registradas 3 pessoas com mais de 65 anos na extrema pobreza. Portanto, 44,7\% dos extremamente pobres do município têm de zero a 17 anos (IBGE, 2010).

No tocante a educação, das pessoas com mais de 15 anos em extrema pobreza, 96 não sabiam ler ou escrever, o que representa $29,1 \%$ dos extremamente pobres nessa faixa etária. Dentre eles, 69 eram chefes de domicílio. A pesquisa revelou, também, que no município havia 37 crianças de 0 a 3 anos na extrema pobreza não frequentando creche, o que representa $63,6 \%$ das crianças extremamente pobres nessa faixa etária. No grupo de 6 a 14 anos, eram 03 (2,3\%) que não frequentavam a escola. Por fim, entre os jovens de 15 a 17 anos na extrema pobreza, 06 estavam fora da escola $(20,1 \%$ dos jovens extremamente pobres nessa faixa etária) (IBGE, 2010).

Passemos, pois, a apresentação dos dados coletados através da aplicação de questionários desta pesquisa nas comunidades constituintes do nosso lócus.

\section{METODOLOGIA}

O loco desta pesquisa foi às escolas municipais da zona rural da cidade de Paraú/RN. Este estudo procurou analisar o nível de pobreza e desigualdade social nas escolas do núcleo rural do município. A escolha metodológica da aplicação do questionário foi firmada em Severino (2007) e Demo (1982). Os dados coletados estão apresentados por intermédio de tabelas e comentários interpretativos.

Tendo sido realizada com os professores e funcionários lotados nas referidas escolas da rede municipal de ensino, que, de forma voluntária, responderam ao questionário impresso, e assinaram 0 Termo de Livre Consentimento e Esclarecimento. 
Os questionários foram aplicados nas escolas das comunidades de Alagamar; Graça; Curralinho e Estrela do Oeste, no período de 03 (três) a 07 (sete) de outubro de 2017(dois mil e dezessete).

Foram entrevistadas 10 (dez) famílias e 04 (quatro) professores, que foram questionados sobre o conceito de pobreza e os fatores sobre a causa da pobreza na zona rural.

\section{APRESENTAÇÃO DOS DADOS COLETADOS VIA QUESTIONÁRIO}

No intuito de alcançarmos os objetivos pretendidos para este trabalho, foram elaborados/aplicados dois questionários mistos (com perguntas objetivas e subjetivas) destinados a funcionários da escola e representante das famílias de cada comunidade. Além de dados específicos, como: função na escola, tempo de atuação, comunidade, idade, sexo, escolaridade e profissão, as perguntas versavam sobre: quanto a versão da escola: visão geral e local acerca da pobreza e desigualdade social, possíveis causas e soluções; quanto a versão da família: composição familiar, renda, acepção de pobreza e desigualdade social, qualidades e deficiências da escola comunitária.

Foram entrevistadas $10(\mathrm{dez})$ famílias na zona rural do município em questão, onde destas, apenas 2 (duas) não se declararam pobre. Segundo seus conceitos elas estão em nível intermediário, sendo que uma delas informou no questionário aplicado ter como renda mensal menos de um salário-mínimo. Somente 1(uma) família afirmou ter renda superior a um salário-mínimo. Em todas as famílias, seus representantes são agricultores, com 3 (três) membros, aproximadamente, por família, dos quais, um ou mais frequentam a escola da comunidade.

TABELA 1: Perfil das famílias entrevistadas nas comunidades rurais[4]

\begin{tabular}{|l|ll|l|l|l}
\hline COMUNIDADE & № & DE & PROFISSÃO & VALOR DA \\
FAMíLIAS & & & RENDA \\
& MENSAL & &
\end{tabular}




\begin{tabular}{|l|l|l|llll|}
\hline ALAGAMAR & 04 & Agricultor & $\begin{array}{l}\text { Menos de um } \\
\text { mínimo }\end{array}$ & sal. \\
\hline $\begin{array}{l}\text { ESTRELA } \\
\text { OESTE }\end{array}$ & 02 & Agricultor & $\begin{array}{l}\text { Menos de } \\
\text { mínimo }\end{array}$ & sal. \\
\hline CURRALINHO & 02 & Agricultor & $\begin{array}{l}\text { Menos de um } \\
\text { mínimo }\end{array}$ & sal. \\
\hline GRAÇA & 02 & Agricultor & $\begin{array}{l}\text { Menos de um } \\
\text { mínimo }\end{array}$ & sal. \\
\hline TOTAL & 10 & & & & \\
\hline
\end{tabular}

Fonte: Arquivo da pesquisa (2017)

Nas escolas rurais, foram entrevistados 9 (nove) profissionais escolares, de ambos os sexos, com faixa etária de 40 a 60 anos, com mais de 4 (quatro) anos de tempo de serviço. Todos residem na zona urbana do município, se deslocando todas as manhãs para a comunidade de sua atuação profissional.

TABELA 2: Perfil dos profissionais escolares das comunidades rurais[5]

\section{№ DE}

COMUNIDADE

\begin{tabular}{|l|l|l|}
\hline & PROFESSOR & A. $\mathbf{S} . \mathbf{G}$ \\
\hline ALAGAMAR & 04 & 0 \\
\hline ESTRELA DO OESTE & 01 & 0 \\
\hline CURRALINHO & 01 & 01 \\
\hline GRAÇA & 01 & 01 \\
\hline TOTAL & 07 & 02 \\
\hline
\end{tabular}

Fonte: Arquivo da pesquisa (2017)

\section{ENTREVISTADOS}

01

02

RC: 103668

Disponível em: https://www.nucleodoconhecimento.com.br/educacao/desigualdadesocial 
Além disso, todos os professores são acompanhados, periodicamente, pelos técnicos em educação da Secretaria Municipal de Educação, onde recebem suporte técnico e pedagógico da equipe. Alguns já atuam a aproximadamente 27 (vinte e sete) anos, gerando um laço afetivo com as famílias e seus respectivos discentes.

No tocante ao aspecto da Desigualdade Social, de todos os profissionais escolares entrevistados, apenas 1 (um) diz não conhecer o conceito de Desigualdade Social. Sendo que 2 (dois) deles consideram baixo o nível da escola e, o restante dos entrevistados, afirmam ter nível médio, e acrescentam que este diminuiu durante os anos. No referente às famílias, quando questionadas sobre o mesmo conceito, apenas 2 (duas) das 10 (dez) entrevistadas disseram que o conhecem. Essa realidade aponta para um contexto em que, mesmo que seus filhos sofram com a desigualdade existente na escola, sua família não sabe o que fazer, qual atitude tomar ou mesmo a quem recorrer a fim de sanar ou remediar a situação na qual seu filho foi ou está sendo exposto.

TABELA 3: Conceito de desigualdade social

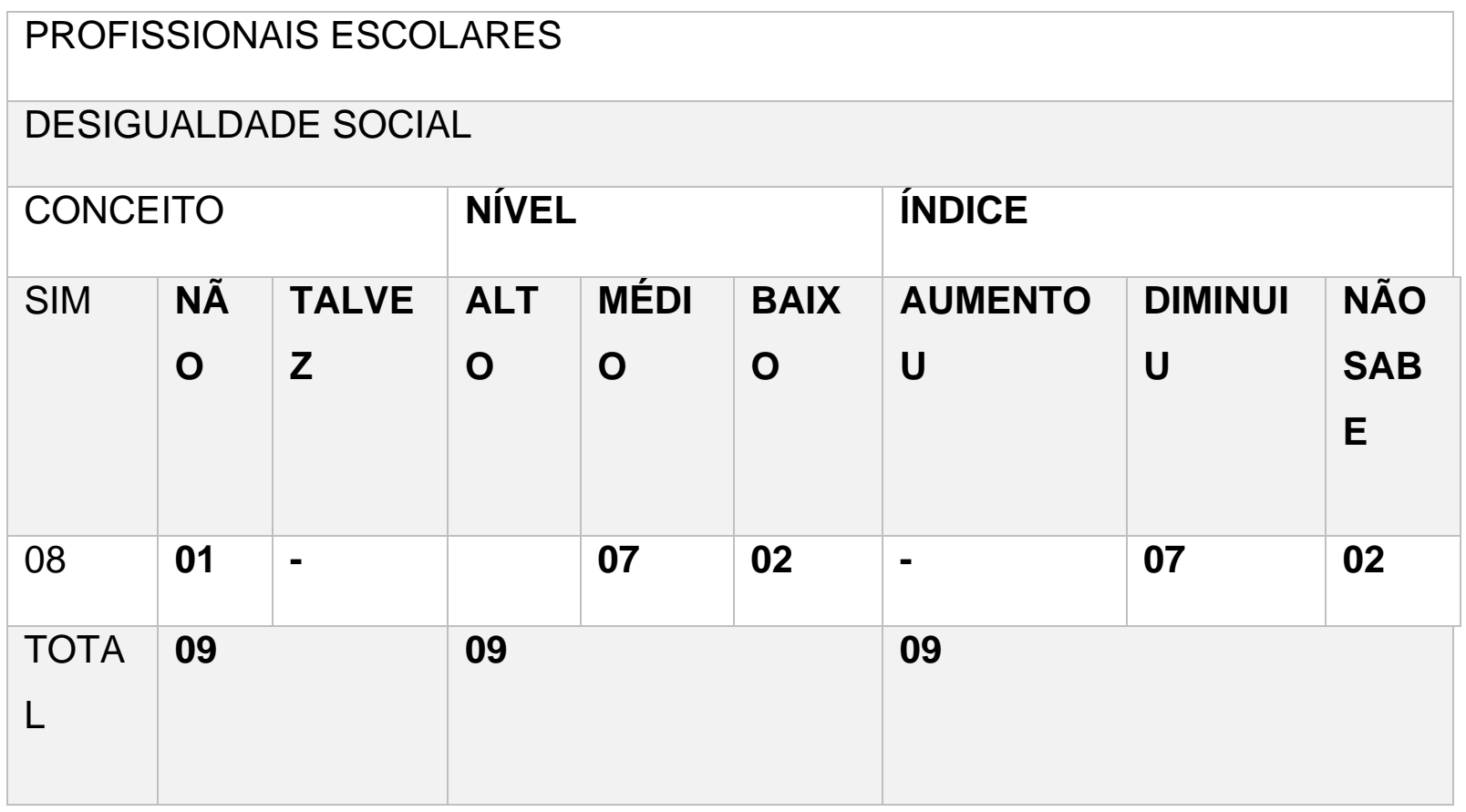

Fonte: Arquivo da pesquisa (2017)

RC: 103668

Disponível em: https://www.nucleodoconhecimento.com.br/educacao/desigualdadesocial 
Sobre os fatores responsáveis pela Pobreza e Desigualdade Social, todos os profissionais entrevistados apontaram fatores como: a falta de emprego; o baixo nível de escolaridade; a renda familiar baixa e a falta de investimento nas políticas públicas. Ainda, 2 (dois) dos entrevistados citaram a mudança da população rural, que foi morar em outras cidades a procura de emprego, sendo este, também, um fator responsável pela geração da Desigualdade Social, uma vez que devido ao baixo número de residentes, diminui-se 0 interesse do poder público pela comunidade rural.

A pobreza na zona rural pode ser entendida como exclusão econômica, o que resulta em exclusão política e social, não permitindo que o sujeito seja ouvido e tenha seus direitos respeitados. Arroyo (2013), diz, que a pobreza, não está só nas favelas, nas ruas, mas também nas escolas. As desigualdades de oportunidades, no que concerne à educação, participação política e cuidados de saúde, são fatores que mantém as pessoas reféns da condição de miséria extrema.

Como solução ou medida de amenização da Pobreza e Desigualdade Social existentes na comunidade rural, os entrevistados, sugeriram um maior investimento na educação e incentivo a instalação de empresas no município.

Ante ao exposto, descrever a desigualdade social dentro das escolas pesquisadas é algo complexo. Os próprios atores destas situações - professor; aluno; família sentem dificuldade em estabelecer um nível de caracterização desta.

A Desigualdade Social e a Pobreza na zona rural são fatores preocupantes, uma vez que as instituições não estão devidamente preparadas para receberem as crianças com suas diferenças e diversidades. As poucas crianças que vão à escola de zona rural se deparam com uma instituição de ensino onde o tempo, espaço e currículo desconsideram os saberes, vivências e experiências de "seus territórios".

Assim, a forma mais viável para enfrentar esse contexto de desigualdade e não efetivação dos direitos, é investir em educação, formando indivíduos capazes de 
interagir com o meio social e transformá-lo, para a diversidade, que as pessoas se sintam mais humanas, respeitando as igualdades e as diferenças.

É notório, pois, que a escola precisa avançar na elaboração de seus currículos, passando a considerar as diversidades culturais, étnicas, sociais, econômicas e políticas que perpassam pelo cotidiano de crianças e adolescentes dos mais variados grupos e comunidades, assim como que se considere, especialmente, a questão da produção, reprodução e manutenção da pobreza, possibilitando aos empobrecidos o "sentir-se pobre", e, ainda, levando a uma reflexão crítica coletiva a todos os atores sociais inseridos no âmbito escolar.

Como afirma Paulo Freire (1987), a educação não é neutra, então, necessitamos de uma escola que se preocupe com a mutação social, que esteja atenta as desigualdades sociais, procurando inibi-las ao máximo, em conjunto com a comunidade, buscando uma sociedade mais igualitária e democrática. Para isso, é preciso repensar suas práticas, sua cultura e sua relação com a sociedade.

\section{CONCLUSÃO}

Durante o desenvolvimento da aplicação do questionário, foi possível observar o nível de pobreza e desigualdade social existentes nas escolas da zona rural do município Paraú/RN. Portanto, retomando a questão norteadora: Qual o nível de pobreza e desigualdade social nas escolas da zona rural do município Paraú? Concluiu-se que a maior parte dos entrevistados se declara pobre e não conhece o conceito de desigualdade social. Chega-se à conclusão de que a pobreza e a desigualdade social nas escolas in loco, são fatores de exclusão política e social, demonstrando a necessidade de políticas públicas que atendam a população presente nestas escolas.

A escola, que é o espaço onde deveria haver a emancipação cidadãos, contribui para o aumento das Desigualdades Sociais, quando não faz o seu papel de preparar o cidadão a sociedade. É fato que a escola, atualmente, está sobrecarregada de 
responsabilidades que vão além do seu papel educativo. O público, por ela atendido, chega com inúmeros problemas pessoais e familiares que, na maioria dos casos, condiciona a sua vida estudantil, levando o educando a enfrentar dificuldades, atrapalhando o seu desempenho educacional.

No decorrer de alguns anos já houve alguns avanços, especialmente fruto das inquietações dos movimentos sociais, por meio de algumas experiências de escolas que se posicionaram na luta contra as desigualdades sociais, instituindo espaços de práticas culturais emancipatórias para alunos e professores que delas participam. Nesse sentido, os avanços parecem estar ainda no campo dos discursos e das perspectivas, maquiando a real situação.

Nas escolas pesquisadas, foi possível identificar que estas não atendem as necessidades dos alunos, tem seus currículos implantados de forma vertical, contemplando a realidade de outras. A despeito disto, como apontado pelos entrevistados e reforçado na literatura pesquisada, a educação, é o meio de se conseguir a emancipação do ser humano e também amenizar as desigualdades sociais. Entretanto as políticas públicas educacionais brasileiras e as práticas pedagógicas ainda não têm permitido que o trabalho educacional nas escolas seja totalmente libertador, haja vista que falta uma proposta pedagógica e curricular voltada para a realidade sociocultural e territorial dos discentes, onde seus saberes e vivências sejam valorizados no âmbito escolar, para que o aluno sinta prazer em ir para a escola, a fim de tornar-se um ser humano emancipado e capaz de inserir-se no meio social como um cidadão conhecedor dos seus direitos e lutador pela erradicação ou, pelo menos, amenização das mazelas sociais que têm incidido na vida e na sobrevivência das minorias.

\section{REFÊRENCIAS}

ARROYO, Miguel Gonzalez. Os coletivos empobrecidosrepolitizam os currículos. In: SACRISTÁN, José Gimeno (Org.). Saberes e Incertezas sobre o Currículo. Porto Alegre: Penso, 2013. 
CASCUDO, Luís da Câmara. Nomes da Terra: Geografia, História e Toponímia do Rio Grande do Norte. Natal: FJA, 1968

INSTITUTO BRASILEIRO DE GEOGRAFIA E ESTATÍSTICA (IBGE). Censo, 2010. Disponível em: http://cidades.ibge.gov.br. Acessado em 07/09/2016.

DEMO, Pedro. Pesquisa Participante, Mito e Realidade. Brasilia: UNB/INEP. 1992.

DESTREMAU, Blandine; SALAMA, Pierre. O tamanho da pobreza: economia política da distribuição de renda. Rio de Janeiro: Garamond, 1999.

DOCUMENTOS HISTÓRICOS DA BIBLIOTECA NACIONAL - 1677/1678. Patentes: 1534-1551. Foraes, Doações, Regimentos e Mandados. Vol. XIII da série e XI dos Documentos. Rio de Janeiro: Augusto Porto, 1929.

FREIRE, Paulo. Pedagogia do oprimido. 13. ed. Rio de Janeiro: Paz e Terra, 1987

GONZAGA, Luiz. A triste partida. RCA Victor, 1964. Disco de vinil.

SEVERINO, Antonio Joaquim. Metodologia do Trabalho Cientifico. 23를 Ed. Ver. E atual. São Paulo: Cortez, 2007.

SMITH, Adam. A riqueza das nações. São Paulo: Abril Cultural, 1983. Vol. II.

YAZBEK, Maria Carmelita. Serviço Social e pobreza. Rev. Katál. Florianópolis v. 13 n. 2 p. 153-154 jul./dez. 2010.

\section{APÊNDICE - NOTA DE RODAPÉ}

[2] No dia da aplicação do questionário o diretor e o coordenador pedagógico não estavam na escola.

[3] De acordo com o IBGE a população estimada do município de Paraú-RNem 2016 é de 3.875 habitantes e sua área territorial, em 2015, de $383,214 \mathrm{~km}^{2}$. 
[4] De cada família foi entrevistado o pai ou mãe. Somente em uma comunidade os dois foram entrevistados.

[5] Os profissionais a quem se refere são os professores e os auxiliares de serviços gerais.

Enviado: Dezembro, 2021.

Aprovado: Dezembro, 2021. 